\title{
Persistent molar pregnancy in an ectopic tubal pregnancy treated with laparoscopic surgery: A case report
}

\author{
Anthony Richards, Kirsten Black, Selvan Pather
}

\begin{abstract}
Introduction: Molar pregnancy presenting as an ectopic pregnancy is very rare with only occasional cases being previously reported. Case Report: A 50-year-old Asian female underwent a successful laparoscopic salpingectomy of an unruptured tubal ectopic pregnancy. The histopathology confirmed a complete molar pregnancy within the tubal specimen. Postoperatively, after an initial fall, there was a gradual increase in her $B$ subunit of human chorionic gonadotropin (B-hCG) levels. The patient requested surgical intervention and she underwent total laparoscopic hysterectomy, left salpingooophorectomy, right oophorectomy and removal of residual right fallopian tube. The histopathology revealed no residual trophoblastic tissue in the excised specimen. Her B-hCG returned to normal postoperatively. Conclusion: This case report is the first example
\end{abstract}

Anthony Richards ${ }^{1}$, Kirsten Black ${ }^{2}$, Selvan Pather ${ }^{3}$

Affiliations: ${ }^{1}$ Department of Gynaecologic Oncology, Royal Prince Alfred Hospital, Sydney Cancer Centre and Department of Obstetrics and Gynaecology, University of Sydney, Camperdown, New South Wales, Australia; 'Women's and Babies Division, Royal Prince Alfred Hospital, Missenden Road, Camperdown, New South Wales, Australia; ${ }^{3}$ Senior Specialist in Gynaecologic Oncology, Sydney Gynaecologic Oncology Group, Sydney Cancer and Royal Prince Alfred Hospital, Missenden Road, Camperdown, New South Wales, Australia

Corresponding Author: Professor Selvan Pather, Senior Specialist in Gynaecologic Oncology, Sydney Gynaecologic Oncology Group, Sydney Cancer and Royal Prince Alfred Hospital, Missenden Road, Camperdown,New South Wales, Australia 2050; $\mathrm{Ph}:+612$ 95156111, Fax: +61 29515 8434; Email: spather@med.usyd.edu.au

Received: 15 March 2012

Accepted: 04 June 2012

Published: 01 April 2013 of persistent molar pregnancy of the fallopian tube being treated with completion surgery and highlights that this is an effective treatment of this rare condition.

Keywords: Ectopic pregnancy, Hydatidiform mole, Hysterectomy, Trophoblastic neoplasms

$$
* * * * * * * * *
$$

Richards A, Black K, Pather S. Persistent molar pregnancy in an ectopic tubal pregnancy treated with laparoscopic surgery: A case report. International Journal of Case Reports and Images 2013;4(4):220-223.

$* * * * * * * * *$

doi:10.5348/ijcri-2013-04-298-CR-7

\section{INTRODUCTION}

Ectopic pregnancy is an important cause of maternal morbidity and occasionally mortality. $1.3-2 \%$ of all reported pregnancies are extrauterine [1]. Quantitative measurements of the $\beta$ subunit of human chorionic gonadotropin (B-hCG) and transvaginal ultrasonography have improved the accuracy of diagnosis and allow earlier detection of ectopic pregnancies than was previously possible. Deaths associated with ectopic pregnancy have declined, though more than three quarters of deaths in the first trimester and $9-13 \%$ of all pregnancy-related deaths are associated with pregnancies outside the uterus [2].

Gestational trophoblastic disease is an uncommon event with an incidence of $1 / 500$ to $1 / 1000$ in the developed world [3]. The most common presentation is that of a primary uterine complete or partial molar pregnancy. Molar pregnancy presenting as an ectopic pregnancy is very rare with only occasional cases being previously reported [4-9]. Previous reports have emphasized that this is associated with a good prognosis 
following laparoscopic salpingectomy. Invasive molar pregnancy and choriocarcinoma have been reported previously and this has usually been treated with chemotherapy.

We present a case of a patient who was noted to have tubal molar pregnancy after a salpingectomy for a suspected ectopic pregnancy and after a period of follow-up was noted to have persistent/invasive disease. The patient opted to have completion surgery carried out and following a total laparoscopic hysterectomy her serum markers normalized.

\section{CASE REPORT}

A 50-year-old Asian female, presented to the emergency department (ED) with vaginal bleeding and pelvic pain following seven weeks of amenorrhea. Pelvic examination showed a normal sized uterus with right adnexal tenderness. Her BhCG level was 19598 IU/L. A subsequent pelvic ultrasound demonstrated a complex right adnexal mass and free fluid in the pelvis, compatible with a right tubal ectopic pregnancy.

The patient underwent a successful laparoscopic salpingectomy of a unruptured right tubal ectopic pregnancy. Her postoperative recovery was uneventful and she was discharged the following day. The histopathology of the surgical specimen confirmed a population of dilated chorionic villi with features compatible with a complete molar pregnancy. No fetal tissues was observed, replaced by a focal area of chorionic villi deep within the muscle layer of the fallopian tube, in keeping with an invasive molar pregnancy.

She was subsequently managed conservatively with serial $\beta$-hCG levels. There was an initial significant fall after surgery (to $20 \mathrm{IU} / \mathrm{L}$ four weeks postoperation), but there was a gradual increase observed in the following three weeks (to $87 \mathrm{IU} / \mathrm{L}$ seven weeks postoperation). Computed tomography scan of the chest, abdomen and pelvis revealed no evidence of metastatic disease. The patient expressed a desire for surgical management, as her pregnancy was unexpected and future fertility was not desired. She subsequently underwent a total laparoscopic hysterectomy, left salpingo-oophorectomy and removal of the right ovary and residual fallopian tube.

The operation was uneventful and revealed evidence of a significant amount of residual fallopian tube on the right side, thought to be the source of the persistent molar pregnancy. The final pathology results revealed no residual trophoblastic disease and her serum B-hCG returned to normal a week after the operation. She was follow-up for 12 months after her surgery and had remained well with normal serum $\beta$-hCG levels.

\section{DISCUSSION}

Previous studies have estimated the incidence of ectopic molar pregnancy to be in the order of 1.5 per 1,000,000 births [3]. Tubal molar pregnancy has been described in several sites, including fallopian tube, cervix, ovary, uterine cornua, a rudimentary uterine horn and a cesarean section scar. Most have been managed with initial surgical management and diagnosis made incidentally with histopathology. In many centres tubal ectopic pregnancy is managed by systemic or intralesional methotrexate without histological confirmation of the pathology. While nearly all of these will be ectopic "normal" pregnancy, a small number are likely to be tubal molar pregnancies that are unrecognized.

The histopathological diagnosis of tubal molar pregnancy is a difficult one complicated by the fact that nontubal molar pregnancies may also exhibit hydropic villi [10-12]. The diagnosis of tubal complete molar pregnancy requires circumferential trophoblastic proliferation, hydrops, scalloped villi, and stromal karyorrhexis associated with diploid DNA on flow cytometry [12]. One paper has suggested the overdiagnosis of ectopic molar pregnancy, with confirmation of the pathology by expert gynecological pathologists only in 6\% of surgical specimens [13]. Furthermore, because of the locally invasive nature of the trophoblast forming the early gestational sac, observed as implantation site fragments in uterine curettage, ectopic pregnancies may be associated with apparent local invasion of surrounding tissues by trophoblast [13].

The persistence of elevated B-hCG after salpingectomy in our patient would imply evidence of correct pathological diagnosis of trophoblastic invasion. Moreover, despite no evidence of persistent trophoblast in the final histology after completion hysterectomy and bilateral salpingooophorectomy, the fall in her serum $\beta$-hCG confirms that there was likely to be a focus of residual disease in the fallopian tube. This presumption was not verified on step sections of the pathological specimen.

The risk of persistent disease after surgery for ectopic molar pregnancy is difficult to quantify, due to the small number of cases reported. Most other cases did not develop persistent gestational trophoblastic disease clinically or require chemotherapy. Hence, the risk for persistent trophoblast is likely to be similar uterine molar gestations [14]. Two previous series have noted if persistent disease in detected the early institution of systemic single agent methotrexate is associated with an excellent outcome [10, 14]. Repeat surgery has been limited to control of intra-abdominal hemorrhage whilst on chemotherapy. We discussed the options of chemotherapy with our patient, but she declined, preferring completion surgery. We were uncertain of the exact location of the recurrent disease and a laparoscopic hysterectomy and bilateral salpingooophorectomy was undertaken rather than a complete salpingectomy.

\section{CONCLUSION}

In our knowledge, this is the first case of persistent molar pregnancy of the fallopian tube being treated with completion surgery and highlights that this is an 
effective treatment of this rare condition. It can be used as an alternative to methotrexate therapy, in the absence of metastatic disease to manage the persistently elevated $\beta$-hCG, following tubal ectopic molar pregnancy.

$* * * * * * * * *$

\section{Author Contributions}

Anthony Richards - Substantial contributions to conception and design, Acquisition of data, Analysis and interpretation of data, Drafting the article, Revising it critically for important intellectual content, Final approval of the version to be published

Kirsten Black - Analysis and interpretation of data, Drafting the article, Revising it critically for important intellectual content, Final approval of the version to be published

Selvan Pather - Substantial contributions to conception and design, Acquisition of data, Analysis and interpretation of data, Drafting the article, Revising it critically for important intellectual content, Final approval of the version to be published

\section{Guarantor}

The corresponding author is the guarantor of submission.

\section{Conflict of Interest}

Authors declare no conflict of interest.

\section{Copyright}

(C) Anthony Richards et al. 2013; This article is distributed under the terms of Creative Commons Attribution 3.0 License which permits unrestricted use, distribution and reproduction in any means provided the original authors and original publisher are properly credited. (Please see www.ijcasereportsandimages.com /copyright-policy.php for more information.)

\section{REFERENCES}

1. Centers for Disease Control and Prevention (CDC). Ectopic pregnancy--United States, 1990-1992. MMWR Morb Mortal Wkly Rep 1995;44(3):46-8.

2. RCOG. Why mothers die 1997-1999: the fifth report of the confidential enquiries into maternal deaths in the United Kingdom 1997-1999. London: RCOG Press 2001.

3. Cunningham FG, Gant NF, Leveno KJ, et al. Gestational trophoblastic disease, In: Williams Obstetrics, 21st edn. New York: McGraw-Hill 2001;835-49.

4. Depypere HT, Dhont M, Verschraegen-Spae MR, Coppens M. Tubal hydatidiform mole. Am J Obstet Gynecol 1993;169(1):209-10.

5. Asseryanis E, Schurz B, Eppel W, Wenzl R, Vavra N, Husslein P. Detection of an atypical invasive mole in an ectopic pregnancy by transvaginal color-flow Doppler. Am J Obstet Gynecol 1993;169(6):1656.
6. Newcomer JR. Ampullary tubal hydatidiform mole treated with linear salpingotomy. A case report. J Reprod Med 1998;43(10):913-5.

7. Zite NB, Lipscomb GH, Merrill K. Molar cornual ectopic pregnancy. Obstet Gynecol 2002;99(5 Pt 2):891-2.

8. Mohamed AA, Sharma SD. Fallopian tube hydatidiform mole. J Obstet Gynaecol 2003;23(3):330-1.

9. Chauhan S, Diamond MP, Johns DA. A case of molar ectopic pregnancy. Fertil Steril 2004;81(4):1140-1.

10. Gillespie AM, Lidbury EA, Tidy JA, Hancock BW. The clinical presentation, treatment, and outcome of patients diagnosed with possible ectopic molar gestation. Int J Gynecol Cancer 2004;14(2):366-9.

11. Muto MG, Lage JM, Berkowitz RS, Goldstein DP, Bernstein MR. Gestational trophoblastic disease of the Fallopian tube. J Reprod Med 1991;36(1):57-60.

12. Burton JL, Lidbury EA, Gillespie AM, et al. Overdiagnosis of hydatidiform mole in early tubal ectopic pregnancy. Histopathology 2001;38(5):409-17.

13. Sebire NJ, Lindsay I, Fisher RA, Savage P, Seckl MJ. Overdiagnosis of complete and partial hydatidiform mole in tubal ectopic pregnancies. Int $\mathrm{J}$ Gynecol Pathol 2005;24(3):260-4.

14. Seckl MJ, Fisher RA, Salerno G, et al. Choriocarcinoma and partial hydatidiform moles. Lancet 2000;356(9223):36-9. 
Access full text article on other devices

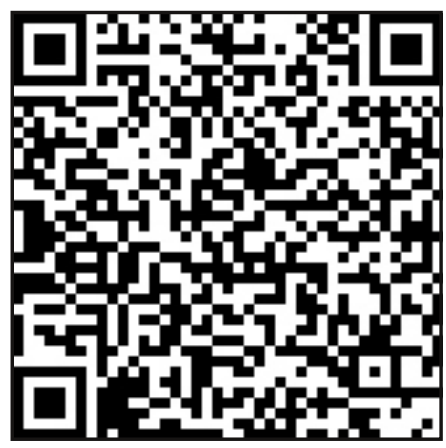

Access PDF of article on other devices

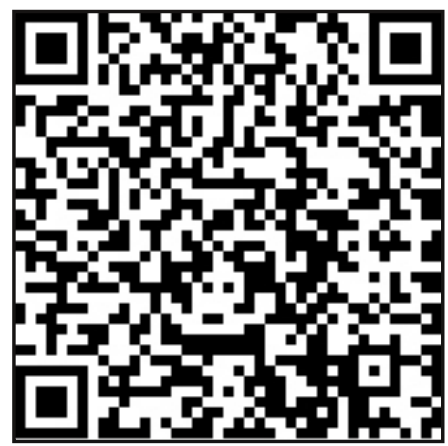

